\title{
Theoretical and methodological approaches of visual sociology in the study of gender
}

\author{
E. V. Bushkova-Shiklina ${ }^{1}$, K. I. Odegova ${ }^{1}$
}

1Vyatka State University, 36 Moscowskaya str., Kirov 610000, Russian Federation

DOI: $10.18255 / 2412-6519-2021-4-392-401$

Research Article

Full text in Russian

One way to comprehend social reality is to watch animation films and animation series that broadcast gender models. In connection with the changes taking place in modern ideas about gender, it will be relevant to study gender roles that function in modern animation cinema. The purpose of the article is to study the theoretical and methodological approaches of visual sociology, used in the study of gender, for further selection of the most optimal methods in the study of gender models broadcast in modern animation cinema. Based on the system-analytical method, an overview of the degree of development of the problems of visual analysis of gender is made; the definitions of the concept of "gender" are considered. The authors believe that the most relevant will be the understanding of gender as a system of sociocultural norms constructed by society, which represent a number of characteristics and can be fixed by the methods of visual sociology. The main approaches of visual sociology are systematized: psychoanalytic, socio-critical, deconstructionist, hermeneutic, semiotic, (post)structuralist and discursive. The most correct methods of visual analysis in the study of gender (video surveillance, photo and video interviews, content analysis) have been substantiated. The authors conclude that for a qualitative analysis of gender problems in animated cinema, it is necessary to use classical methods of visual sociology in combination with additional methods of sociology (hermeneutic analysis, semiotic interpretation, focus groups).

Keywords: theoretical and methodological approaches, visual sociology, visual culture, visual methods, gender, animation cinematography

INFORMATION ABOUT THE AUTHORS

\begin{tabular}{r|l}
$\begin{array}{r}\text { Bushkova-Shiklina, Elvira V. } \\
\text { (correspondence author) }\end{array}$ & $\begin{array}{l}\text { E-mail: elvira_bsh@mail.ru } \\
\text { Doc. Sc. (Sociology), Associate Professor }\end{array}$ \\
\begin{tabular}{l|l} 
Odegova, Ksenia I. & $\begin{array}{l}\text { E-mail: NakatsuSobi@yandex.ru } \\
\text { Graduate student }\end{array}$
\end{tabular}
\end{tabular}

For citation: Bushkova-Shiklina E. V., Odegova K. I. Theoretical and methodological approaches of visual sociology in the study of gender // Social'nye i gumanitarnye znanija. 2021. Vol. 7, No 4. P. 392-401. (in Russ.)

(C) Bushkova-Shiklina E. V., Odegova K. I., 2021

This is an open access article under the CC BY license (https://creativecommons.org/licenses/by/4.0/) 


\title{
Теоретико-методологические подходы визуальной социологии в изучении гендера
}

\author{
Э. В. Бушкова-Шиклина ${ }^{1}$, К. И. Одегова ${ }^{1}$
}

${ }^{1}$ Вятский государственный университет, ул. Московская, 36, Киров, 610000, Российская Федерация

DOI: $10.18255 / 2412-6519-2021-4-392-401$

УдК 316.1

Научная статья

Полный текст на русском языке

Одно из следствий современной социальной динамики - трансформация социальноролевого портрета представителей различных страт, в частности, гендерных моделей поведения. Это находит отражение в массовой культуре, в том числе анимационных фильмах и сериалах. Целью статьи явилось изучение теоретико-методологических подходов и методов визуальной социологии, применяемых в исследовании гендерных моделей, транслируемых в современном анимационном кинематографе. На основе системно-аналитического метода сделан обзор степени разработанности проблем визуального анализа гендера, рассмотрены дефиниции понятия «гендер». Авторы считают, что наиболее актуальным будет понимание гендера как системы социокультурных норм, конструируемых обществом, которые представляют собой ряд характеристик и могут быть зафиксированы методами визуальной социологии. Систематизированы основные подходы визуальной социологии: психоаналитический, социально-критический, деконструкционистский, герменевтический, семиотический, (пост)структуралистский и дискурсивный. Обоснованы наиболее корректные методики визуального анализа в исследовании гендера (видеонаблюдение, фото- и видеоинтервью, контент-анализ). Авторами делается вывод о том, что для качественного анализа проблем гендера в анимационном кинематографе необходимо использовать классические методы визуальной социологии в сочетании с дополнительными приемами (герменевтический анализ, семиотическая интерпретация и пр.).

Ключевые слова: визуальная социология, визуальные методы, гендер, гендерные роли, гендерная репрезентация, анимационный кинематограф

ИНФОРМАЦИЯ ОБ АВТОРАХ

Бушкова-Шиклина, Эльвира $\mid$ E-mail: elvira_bsh@mail.ru

Васильевна ORCID: 0000-0003-3929-5240

(автор для корреспонденции) Кандидат социологических наук, доцент кафедры

культурологии, социологии и философии

Одегова, Ксения Игоревна $\mid$ E-mail: NakatsuSobi@yandex.ru

ORCID: 0000-0003-4745-6032

Магистрант II курса кафедры культурологии, социологии и философии

Для цитирования: Бушкова-Шиклина Э. В., Одегова К. И. Теоретико-методологические подходы визуальной социологии в изучении гендера // Социальные и гуманитарные знания. 2021. Том 7, № 4. C. 392-401.

(C) Бушкова-Шиклина Э. В., Одегова К. И., 2021

Статья открытого доступа под лицензией СС BY (https://creativecommons.org/licenses/by/4.0/) 


\section{Введение}

Одним из способов постижения социальной действительности является просмотр анимационных фильмов и сериалов, являющихся трансляторами различных моделей поведения, в том числе и гендерных, которые в современном мире начинают меняться в сторону смещения или замещения друг друга, доводя многих людей до кризиса гендерной идентичности [1; 2]. Современному обществу свойственно клиповое мышление, характеризующееся восприятием мира через короткие яркие образы. Отсюда возникает интерес людей к анимационным фильмам и сериалам, отличающимся красочностью образов и разнообразием сюжетов.

Для более глубоко понимания специфики функционирования гендерных ролей в современном анимационном кинематографе был проведен анализ и систематизированы подходы и методы визуальной социологии, которые на сегодняшний день достаточно разнообразны. Общей особенностью данной группы методов и методик является акцент на изображении как способе отражения социальной реальности, что позволяет изучать любые аспекты социальной жизни общества, транслируемые в анимационном кинематографе. Целью статьи является изучение теоретико-методологических подходов визуальной социологии, применяемых в исследовании гендера, для дальнейшего выбора наиболее оптимальных методов при изучении гендерных моделей, транслируемых в современном анимационном кинематографе.

Визуальная социология является достаточно молодым направлением, которое сложно рассматривать как отдельную отрасль, но возможно - как особую «методологию исследования визуальных данных» [3], объектом исследования которой является социальная реальность, транслируемая через изображения и другие визуальные объекты. При этом сами визуальные изображения могут пониматься как механические копии социальной реальности, способы соотнесения человека с определенной группой, методы маркирования социального статуса индивида, средства влияния на сознание, связь со временем, пространством, событиями и отображение представлений о моделях поведения [4].

Визуальная социология как способ социологического познания привлекает к себе внимание многих исследователей. Наиболее авторитетным теоретиком визуальной социологии является П. Штомпка, который занимался визуальным анализом фотографии как способа познания общества [5]. Теоретическими и практическими исследованиями в рамках социологии кино как одного из направлений визуальной социологии занимается М. И. Жабский [6], специализирующийся на отечественном кинематографе. Историей становления и развития визуальной социологии занимаются Л. И. Верховод и О. В. Сергеева, рассматривая также основные идеи и подходы в визуальной социологии [7; 8]. А. М. Дьяконова, Н. Д. Орлов, А. А. Коржавина, В. Р. Кравцова и др. в своих работах раскрывают центральные понятия визуальной социологии и основные подходы к изучению визуальной культуры [4]. В. В. Колодий задает теоретико-методологические основания использования фотографии и других визуальных искусств в изучении общества [9]. 
В рамках визуальной социологии ряд исследований посвящен проблемам гендера, отраженным в аудиовизуальных видах искусства. Так, в работах Е. Н. Гоголевой, Е. И. Медведевой, К. Расмуссен [10; 11; 12] анализируются современные рекламные видеоролики на предмет отражения в них гендерных стереотипов. Несмотря на то, что исследователями изучается реклама из разных областей (автомобили, спорт) и стандартная телевизионная реклама, транслируемая на одном из федеральных каналов России, все они приходят к выводу, что в современной рекламе сохраняются стереотипные образы мужчины и женщины, в которых первый выступает как сильный и умный герой, вторая - как мягкая, сексуальная, зависимая.

Исследования функционирования гендерных ролей в игровом кинематографе представлены работами К. Вальдеррама-Бургос, Б. Невина и О. В. Рябова [13; 14; 15], в которых внимание акцентируется на женских образах. Б. Невин [16] обратился к фильмам французского режиссера Ж. Ренуара «Правила игры» (1939) и «Золотая карета» (1952), отметив двойственность изображаемых им героев. Так, исследователь считает, что главные героини находятся в угнетении со стороны мужчин (несчастливый брак, активные ухаживания со стороны мужчин), при этом обе занимают активную позицию (общение с бывшим возлюбленным и план побега, отказ от ухаживаний и приоритет профессии). Но, как отмечает Б. Невин, Ж. Ренуару не удалось отразить точки зрения женщин, так как в итоге его героини не меняют свои гендерные роли.

O. В. Рябов [15] анализирует образы женщин в советских фильмах, снятых во время Великой Отечественной войны, которые использовались для утверждения советской идентичности. Исследователь приходит к выводу, что женские образы делились на «своих» (советских женщин, любящих родину, обладающих добротой, состраданием, стойкостью и ненавистью к врагу) и «чужих» (женщин нацистской Германии, неверных русским мужьям и СССР). К. Вальдеррама-Бургос [13] же рассматривает гендерные роли, представленные в современном колумбийском кинематографе, на примере фильмов «Светлячки» (2015) и «Промахи» (2013). Исследователь считает, что два этих фильма, снятые режиссерамиженщинами, меняют представления о традиционных гендерных ролях женщин, выводя гендерные и сексуальные практики из маргинальных в актуальные (лесбиянство, женское сексуальное самоисследование, оргазмы). Таким образом, в игровом кинематографе гендерные роли чаще всего представлены образами женщин, которые функционируют как в традиционном виде (добрая, послушная, сострадательная), так и в новых формах (активная, практикующая иные сексуальные практики).

В рамках анализа репрезентации гендера в аудиовизуальном искусстве есть также работы, посвященные разбору образов в анимационных фильмах разных стран [16; 17; 18]. Однако остаются не рассмотренными вопросы, связанные с транслированием гендерных моделей и стереотипов в анимационном кино, которые можно зафиксировать методами визуальной социологии.

Прежде чем перейти к систематизации методов визуальной социологии, используемых для изучения репрезентации гендера в анимационном кинематографе, операционализируем термин «гендер». 
В силу того, что исследования гендера и сам термин появились только во второй половине XX века, вызвав ряд споров о соотношении «пола» и «гендера» $[19$, с. $8 ; 20$, с. 94], до сих пор сохраняется проблема дефиниции понятия. Так, изначально термин был использован Дж. Мани в 1955 году для различения биологического пола и социальной роли [21]. В конце 1960-х годов термин начинает активно использоваться в научном обиходе, становясь противопоставлением биологическому полу и означая социокультурные и социопсихологические характеристики пола [20, с.94]. Со временем в социологии возникает несколько подходов к пониманию гендера, в которых он рассматривается как социальная конструкция (К. Уэст, Д. Зиммерман), как стратификационная категория (Г. Г. Силласте, Э. Гидденс), как культурная метафора (Т. Клименкова) [19, с. 9; 20, с. 95].

Поэтому под гендером можно понимать систему социокультурных норм, конструируемых обществом, которым индивиду необходимо следовать в зависимости от его биологического пола. То есть гендер содержит в себе ряд характеристик (визуальных, вербальных, психологических), которые могут быть зафиксированы различными методами, в том числе и методами визуальной социологии.

В рамках гендера обычно принято выделять три типа: маскулинный, фемининный и андрогинный, для которых свойственны определенные характеристики (независимость, напористость, уступчивость, мягкость, адаптивность, добросовестность и т. д.), проявляющиеся в разных сферах жизни человека (отношения, карьера, семья, здоровье и др.). Для визуального анализа наиболее значимы такие наблюдаемые проявления гендера, как действия людей, их мимика, жесты, позы, одежда, прически (волосы), аксессуары, макияж, особенности тела, которые создают общее впечатление о субъекте и раскрывают его глубинные характеристики.

\section{Возможности визуальной социологии в вопросах изучения социальной жизни и гендера как одного из ее проявлений}

В социально-гуманитарной науке сложилось несколько подходов к изучению визуальной культуры, среди которых Т. В. Вдовина выделяет психоаналитический, социально-критический, деконструкционистский, герменевтический, семиотический, структуралистский и дискурсивный подходы [22, c. 17].

Психоаналитический подход был основан 3. Фрейдом, который занимался анализом произведений искусства. Представители этого направления прослеживали связи между визуальными объектами и человеческим сознанием, так как ими было доказано, что человеческое подсознание взаимодействует с сознанием через различные образы. Поэтому объектом внимания в рамках психоаналитического подхода выступали личные травмы, комплексы и подавленные желания авторов, которые отражались в их произведениях.

На основе психоанализа, неомарксизма, постструктурализма и других идей появился социально-критический подход (Ч. Миллс, Э. Фромм), представители которого в своих исследованиях рассматривают визуальную репрезентацию раз- 
ных рас, гендеров, социальных классов или групп, визуальные проявления определенного социального порядка. Исследователей интересуют вопросы власти, подавления человека и идеологии, проблемы умалчивания и отчуждения, репрезентации и интерпретации.

Благодаря широкой трактовке текста (визуальное изображение как текст) социально-критический подход способствовал появлению деконструктивизма, основанного на принципах диалогизма процесса образования смыслов, интертекстуальности (отсылки к другим текстам), отрицания традиционных толкований. Эти принципы дают возможность найти в визуальных изображениях скрытые смыслы, которые могут быть не обнаружены при обычном анализе произведений, что позволяет использовать деконструктивистский подход как дополнительный метод анализа текстов.

Близким подходом к деконструктивизму является герменевтика (А. Шюц, Г. Гарфинкель), подразумевающая интерпретацию и понимание текстов, состоящих из определенных знаков, реализующих некую субъективность другого. Используя способность поставить себя на место другого, понять его мотивы и переживания, то есть эмпатию, представители герменевтического подхода конструируют мир невидимых субъективных состояний, раскрывающий смысл произведений [Там же. С. 17-21].

Кодированием и декодированием знаков, содержащихся в изображениях, занимается семиотический подход (Р. Барт, У. Эко, М. М. Бахтин), в котором изображение воспринимается как аналог реальности. При этом интерпретация знака зависит от выбранного кода восприятия, который имеет два значения: денотативное (прямое значение, отсылающее нас к реальному субъекту, объекту) и коннотативное (дополнительные семантические или стилистические ассоциации, связанные с культурой).

Представители (пост)структурализма (П. Бурдье, Ж. Деррида, С. Холл) большое внимание уделяли фотографии как одному из средств отражения социально значимой реальности. По их мнению, в момент анализа произведения важно учитывать не только то, что изображено, например, на фотографии, но и место и время его создания, тех, кто его создает, и тех, кто на него будет смотреть. Поэтому в рамках (пост)структурализма большой акцент делается на изучении культурных норм и ценностей, определенных стандартов поведения, отраженных в визуальных произведениях [4, с. 206-210].

В рамках дискурсивного подхода поддерживается идея о том, что смысл визуального сообщения может меняться в зависимости от интерпретатора. Поэтому целью дискурсивной интерпретации ставится выяснение смыслов, которыми наделяется визуальное сообщение благодаря аудитории. При этом интерпретация зависит от опыта интерпретаторов, то есть идей, традиций и установок, характерных для этой аудитории [22, с. 24].

Говоря о визуальной культуре как современном явлении, можно согласиться с определением С. Г. Ушкина о том, что она представляет собой знаковую систему, формирующую в сознании индивида определенные стереотипы и образцы поведения [23, с. 203]. Эти образцы могут транслироваться в произведениях живописи, графики, скульптуры, фотографии, кино- и анимационных фильмах и т. д. 
На основе перечисленных подходов можно выделить методы, применяемые для изучения гендера в источниках визуальной культуры [3]. М. Н. Богданова отмечает, что выделение особых «визуальных методов» не оправдывает себя, так как в их основе лежат уже известные традиционные методы социологии: наблюдение, опрос (фото- и видеоинтервью, фокус-группы) и анализ документов (в частности, контент-анализ). Специфическим же становятся способы реализации данных методов и объекты анализа.

Для метода наблюдения фото- и видеоматериал используется как средство фиксации социальной реальности, позволяющее за счет его визуальной фиксированности неоднократно возвращаться к изучаемой проблеме, раскрывая ее новые аспекты.

Метод фото- и видеоинтервью активно используется сегодня как самостоятельный и вспомогательный (партисипативный) метод [24]. При проведении фото- и видеоинтервью визуальный материал может выступать в качестве стимула для интервьюируемого: в виде автографии, фото-вопроса или фото-отклика [Там же]. Данный метод позволяет узнать значение отснятого материала для респондента, вскрыть глубинные психические особенности человеческой деятельности, определенные комплексы, предрассудки и стереотипы. То есть благодаря методу фото- и видеоинтервью можно выяснить представления общества о гендерных моделях и стереотипах, которые у них ассоциируются с персонажами из анимационных фильмов.

Дополнительным социологическим методом, который можно применить для изучения транслирования гендера в анимационных фильмах, является метод фокус-групn, проводимых на определенную тематику с использованием фотографий или видео (реклама, кинофильмы и анимационные фильмы). Данный метод позволяет сосредоточить внимание респондентов на смысловой стороне визуального материала и социальных, культурных, политических проблемах, заложенных в нем. При изучении гендерных моделей, содержащихся в анимационных фильмах, фокус-группы позволяют сформировать картину общественного мнения по данной проблеме.

Благодаря контент-анализу можно установить содержательные элементы визуального сообщения за счет его стандартизированной техники проведения, позволяющей обработать большой массив данных, и возможности избежать влияния исследователя на процесс получения данных. В изучении гендерных типов в анимационных фильмах контент-анализ применим к массивам разнообразных текстов: фраз, содержания костюмов, обстановки и пр.

По мнению П. Штомпки, при изучении визуального материала немаловажными являются герменевтический анализ и семиотическая интерпретация, которые также могут быть использованы для анализа гендерных моделей героев анимационных фильмов. Посредством герменевтической методологии возможно рассмотреть мотивацию создателей анимационных фильмов, цели их деятельности, ориентации на определенную целевую аудиторию [5, с. 78]. Данный метод дает возможность понять контекст создания образов анимационных героев, раскрыть особенности данных образов. Семиотическая интерпретация позволяет 
подробно проанализировать встречающиеся визуальные образы, раскрыть заложенные в них символические значения, а точнее - реализуемые героями гендерные модели и стереотипы поведения.

Как показывает практика, в современных социально-гуманитарных исследованиях репрезентации гендера в анимационном кинематографе некоторые из вышеперечисленных методов активно используются, но при этом акцент в них смещен на анализ женских образов, оставляя практически без внимания мужские персонажи. Так, например, Е. Н. Потапова и Ю. Гарабедян [25; 18] на примере популярных диснеевских анимационных фильмов («Белоснежка и семь гномов» (1937), «Алладин» (1992), «Красавица и чудовище» (1995), «Храбрая сердцем» (2013), «Моана» (2017) и др.) прослеживают трансформацию образов героинь за период с 1937 г. до современности. А. М. Обухова, Ю. В. Шмарион, А. В. Землянская [26; 27] исследуют гендерные стереотипы в таких анимационных сериалах для девочек, как «Winx» и «Monster High», отмечая изменения в гендерных моделях в сторону феминизации и андрогинизации. П. Шихавцова для своего исследования выбрала современные полнометражные анимационные фильмы с рейтингом не ниже 7,0 на сайте IMDb, но при этом сделала упор на анализ женских образов. Таким образом, анализ источников по указанной проблеме актуализирует необходимость использования более разнообразных подходов к изучению гендерных типов в анимационных фильмах и расширения тематики рассматриваемых вопросов, например, обращение внимания на мужские образы или самые кассовые фильмы последних лет.

\section{Заключение}

Проблема трансформации гендера, транслируемая в СМИ, кино, книгах и телевидении, в современном обществе стоит достаточно остро: появляются новые идентичности, требующие более подробного изучения. Исходя из того, что гендер как система социокультурных норм, конструируемых обществом, содержит в себе ряд характеристик (визуальных, вербальных, психологических), его можно изучать помощью методов визуальной социологии, объектом исследования которой является социальная реальность, транслируемая через изображения и другие визуальные объекты.

Основными источниками исследования гендерных моделей и стереотипов поведения в современной визуальном искусстве являются игровой кинематограф и видео-реклама. Исследования гендерной репрезентации в анимационном кинематографе немногочисленны, но актуальны в связи с востребованностью данного жанра среди молодежи.

Визуальная социология, являясь комплексным междисциплинарным направлением, формирует особую синтетическую методологию исследования визуальных данных. В связи с этим основными теоретико-методологическими подходами к анализу визуальных образов выступают: психоаналитический, социально-критический, деконструктивистский, герменевтический, семиотический, дискурсивный, постструктуралистский и пр. Основываясь на этих подходах и используя такие классические методы визуальной социологии, как видеона- 
блюдение, фото- и видеоинтервью, содержательный визуальный анализ и контент-анализ, а также дополнительные методы (герменевтический анализ, семиотическая интерпретация, фокус-группы), можно провести качественный анализ проблем гендера в анимационном кинематографе.

\section{Ссылки / References}

1. Запольская А. Б. Метод фотоинтервью в социальных исследованиях: аналитический обзор // Социология: 4М. 2014. № 39. С. 127-156.

2. Gender Dysphoria in Adults: An Overview and Primer for Psychiatrists / W. Byne, D. H. Karasic, E. Coleman, A. E. Eyler, J. D. Kidd // FOCUS The Journal of Lifelong Learning in Psychiatry. 2018. № 18 (3). P. 336-350.

3. Богданова Н. М. «Визуальная социология» - новая наука или особый угол зрения? // Социологический журнал. 2012. № 3. С. 67-69.

4. Визуальная социология. Основные подходы и проблемное поле / А. М. Дьяконова, Н. Д. Орлов, А. А. Коржавина, В. Р. Кравцова // Аллея науки. 2019. Т. 1. № 1 (28). С. 273-280.

5. Штомпка П. Визуальная социология. Фотография как метод исследования: учебник / Пер. с польск. Н. В. Морозовой; авт. вступ. ст. Н. Е. Покровский. М.: Логос, 2007. $168 \mathrm{c}$.

6. Социология и кинематограф / [М. И. Жабский, К. А. Тарасов, Ю. У. Фохт-Бабушкин и др.]; под общ. ред. М. И. Жабского; Министерство культуры Российской Федерации, Научно-исследовательский институт киноискусства. М.: Канон+, 2012. 599 c.

7. Верховод Л. И. Эвристический потенциал концепции визуальной социологии П. Штомпки в исследовании социального неравенства // Актуальные научные исследования в современном мире. 2017. № 2-8 (22). С. 41-48.

8. Сергеева О. В. Исследовательское поле визуальной социологии // Федеральный образовательный портал ЭCM. URL: http://ecsocman.hse.ru/data/2010/09/03 /1214990144/09_Sergeeva.pdf (дата обращения: 02.06.2021).

9. Колодий В. В. Визуальность как феномен и ее влияние на социальное познание и социальные практики: автореф. дис. ... канд. филос. наук: 09.00.11. Томск, 2011. 28 c.

10. Гоголева Е. Н. Гендерные стереотипы в телевизионной рекламе как отражение гендерного неравенства // Женщина в российском обществе. 2019. № 1. С. 77-86.

11. Медведева Е. И. Гендерные стереотипы и неомифологизмы в рекламе автомобилей // Женщина в российском обществе. 2019. № 1. С. 87-96.

12. Gender Marginalization in Sports Participation through Advertising: The Case of Nike / K. Rasmussen, M. J. Dufur, M. R. Cope, H. Pierce // Int. J. Environ. Res. Public Health. 2021. № 18. 22 p.

13. Valderrama-Burgos K. Transgressive Female Sexuality and Desire in Contemporary Colombian Cinema: Hermida's La luciérnaga and Rodríguez's Señoritas // Latin American Perspectives. 2021. Vol. 48. №. 2. P. 108-122. 
14. Nevin B. Female agency in the films of Jean Renoir // French Cultural Studies. 2021. Vol. 32 (4). P. 338-402.

15. Рябов О. В. Символические границы в политике советской идентичности: гендерное измерение (На материале кинематографа Великой Отечественной войны) // Женщина в российском обществе. 2020. № 2. С. 10-25.

16. Байриева А. Э. Гендерные модели в зарубежных и отечественных мультипликационных фильмах // Социальные и гуманитарные науки: теория и практика. 2019. № 1 (3). С. 406-415.

17. Шихавцова П. Гендерные режимы в мультфильмах или о том, какой должна быть современная Золушка // Интеракция. Интервью. Интерпретация. 2020. Т. 1. № 1. C. $65-80$.

18. Garabedian J. Animating Gender Roles: How Disney is Redefining the Modern Princess // James Madison Undergraduate Research Journal. 2014. № 2.1. P. 22-25. URL: https://commons.lib.jmu.edu/jmurj/vol2/iss1/4/ (дата обращения: 02.06.2021).

19. Баранихина А. П. Гендер и пол: проблема гендерной социализации в современных научных исследованиях // Традиционные национально-культурные и духовные ценности как фундамент инновационного развития России. 2019. № 2 (16). С. 8-11.

20. Понятие «гендер» в современном научном дискурсе / Ю. Г. Тищенко, И. А. Тищенко, Н. И. Василюк, С. В. Черницкая // Вестник ЮРГТУ (НПИ). Серия: Социальноэкономические науки. 2020. № 1. С. 93-99.

21. Кон И. С. Пол и гендер. Заметки о терминах // Псевдология. URL: http://www.pseudology.org/Kon/Articles/SexGenderTermins.htm (дата обращения: 02.06.2021).

22. Вдовина В. Т. Визуальные исследования: основные методы и подходы // Вестник РуДН. Серия: Социология. 2012. № 1. С. 16-26.

23. Ушкин С. Г. Визуальная социология: интеракционистский, семиотический и постструктуралистский подходы // Вестник ТГУ. Философия. Социология. Политология. 2015. № 1. С. 203-213.

24. Запольская А. Б. Метод фотоинтервью в социальных исследованиях: аналитический обзор // Социология: 4М. 2014. № 39. С. 127-156.

25. Потапова Е. Н. Роль эмансипации и феминизации в формировании женского образа на примере анимации «The Walt Disney Company» // Филологические науки. Вопросы теории и практики. 2017. № 5-3 (71). С. 130-133.

26. Обухова A. М. Гендерные стереотипы в анимационном фильме (на материале «Winx Club и интернет-сайтов, посвященных мультфильмам») // Молодежь третьего тысячелетия: сборник научных статей / [Отв. ред. С. В. Белим]. Омск: Изд-во Ом. гос. унта, 2018. С. 1468-1471.

27. Шмарион Ю. В., Землянская А. В. Женский образ в советских и зарубежных мультфильмах // Вопросы образования и науки: сборник научных трудов по материалам международной научно-практической конференции 30 ноября 2017 г. Тамбов: Консалтинговая компания Юком, 2017. С. 166-170. 